highly esteemed by the Romans, as we know from Juvenal; but there are no grounds for imagining that it was in those times imported into Rome from Britain. The facility of transport was not then so great as it is at present; and a gamy flavour was probably not so much relished by the Romans as it is said to have been by our King George the First, who preferred oysters a week old at Hanover to those which he afterwards got in England.

Within the last few years the "periwinkle"' (Littorina litorea, L.), which is a favourite delicacy of our poorer classes, has spread with unusual rapidity along the eastern shores of the North American continent. Mr. Arthur F. Gray, in Science News for April, 1879, attributed its origin to Europe. It certainly does not seem to have been observed in America by Gould or any other conchologist before 1870 .

Preeminent among land shells, as a dainty article of food in France, is Helix pomatia, L. We are more fastidious or more conservative in our gastronomic notions. It is a mistake to suppose that the Romans, when they possessed and inhabited Great Britain, brought this snail with them to indulge their luxurious tastes. In all probability it was not even known to them, because another species ( $H$. lucorum, Müller) takes its place in Central Italy. $H$. pomatia has not been found at Wroxeter or York, or in any other part of England or Wales where the Romans built cities or had important military stations. Among the debris of an extensive Roman villa discovered in Northamptonshire, in which the shells of cockles, oysters, mussels, and whelks abounded, not one of $H$. pomatia occurred, although at Woodford, a few miles distant, that species is plentiful in a living state. J. GWYN JEFFrEYS

\section{THE ALFIANELLO METEORITE}

SIGNOR DENZA, Director-General of the Italian Meteorological Association, sends us an account of the remarkable aerolite which fell in the province of Brescia on February $I 6$, and to which we referred last week. On that date, at 2.43 p.m. local time, a strong detonation was heard in many places of the province of Brescia and even in the neighbouring provinces of Cremona, Verona, Mantua, Placenza, and Parma. The detonation was quite awful in the commune of Alfianello, in the district of Verolanuova, Brescia. This was found to be caused by a meteorite which exploded a few hundred yards above Alfianello. A peasant saw it fall in the direction of N.E. to S.W., or, more exactly, N.N.E. to S.S.W, at a distance of about I 50 yards. When the meteoric mass fell to the earth, it produced on the ground, in consequence of the transmission of the shock, a movement similar to that of an earthquake, which was felt in the surrounding districts; the telegraph wires oscillated and window frames shook. Before the meteorite fell a confused commotion was seen in the sky, and immediately after a prolonged noise was heard similar to that of a tram moving rapidly along the rails. No light was seen ; but the meteor must have been accompanied, as usual, by a light vapour, produced by the volatilisation of the substance melted at the surface; for some of those who saw it fall compared it to a chimney falling from the sky, and surmounted by a,wreath of smoke. The meteorite fell in a field about 300 yards south-west of Alfianello. It penetrated the ground obliquely, nearly in the same direction as it was seen moving in the air, from east to west, sinking to the depth of about a yard, deducting the height of the meteoric mass. The peasants who saw it fall and who were the first to touch it, found it somewhat hot. The meteorite fell entire, but unfortunately was soon broken to pieces and carried away by the crowd who gathered to see the strange sight. The form was ovoid, but a little flattened at the centre; the under part was broad and convex, presenting the $t, r m$ of a cauldron; the upper part was truncated. The surface was covered with the usual blackish crust, and studded with small concavities, partly separate, partly grouped together.

As to the dimensions and weight of the aerolite, the estimates differ. According to the evidence of some, its height was about 75 centimetres, greatest breadth 60 centimetres, and its volume about 25 cubic decimetres. Its weight has been variously estimated at 50, 100, 200, and 250 kilograms. Its real weight was probably not much under 200 kilograms. It is certain that Prof. Bombicci carried more than 25 kilograms to Bologna, to add to the rich collection of meteorites in the Mineralogical Museum of the University; that a specimen weighin $13 \frac{1}{2}$ kilograms was taken possession of by MM. Ferrari, the owners of the field in which the meteorite fell; that about 40 kilograms remained in possession of other persons; that the municipality of Alfianello sent a specimen of 5 kilograms to the Athenæum of Brescia; and that two pieces weighing i2 kilograms each were thrown into a stream and lost; without speaking of a considerable quantity of small fragments, distributed here and there, of which Signor Denza possesses four, of a total weight of 39 grammes.

By its structure the Alfianello meteorite belongs, according to Prof. Bombicci, to the sporasiderite-oligosiderite group, being almost identical with the New Concord (Ohio) meteorite. The substance is finely granulated, of an ashy grey; the bright glossy surface has elements showing varied gradations of colour. Metallic particles abound; they are found scattered like small nuclei, in which are iron and perhaps one of its alloys; in brilliant crystalline aggregations, of a yellowish or bronze white. Circles of rust of a yeilowish brown rapidly form around the particles of iron In the places where there are no metalliferous nuclei, the grains of iron are attached to the stony portion in the proportion of 68 per 1000 of weight. The blackish crust is rough, and to some extent rugged in some parts of the surface, and rather smooth and uniform in others; in general it is somewhat lustrous. The total specific weight of the stone is from 3.47 to 3.50 . The chemical analysis of the meteorite is being made in two different laboratories at Bologna. Signor Denza's informaticn bas been obtained from Prof. Bombicci of Bologna University, and from Professors Briosi, Ragazzoni, and Casali if Brescia.

\section{THE SHAPES OF LEAVES ${ }^{1}$}

\section{IV.-Special Types in Special Environments}

F ROM the previous papers it will be clear that degree of subordination to the stem accounts in large measure for the extent to which leaves vary from the primitive ovate-lanceolate type. Where they are still so most subordinated, there will be a strong tendency towards the long pointed ribbon-like form, and also a marked inclination towards decurrence. This combination of peculiarities is well seen in several thistles, and in comfrey, as also to a less extent in many epilobes and stellarias. Compare Verbascum thapsus, and other mulleins. From these extreme cases, in which leaf and stem are not fully differentiated from one another, one can trace several gradations, through square stems with sessile leaves (as in certain St. John's worts) up to merely sessile stemleaves, or leaves that clasp the stem with pointed or rounded auricles. Wherever lines exist along the stem, they may be observed in pairs up to the point where a leaf is given off, and they are undoubtedly surviving marks of the primitive unity of stem and leaf. The same may be said of rows of hairs, like those of Stellaria media and of Veronica chamcedrys. There can be little doubt 